\title{
28 Research Soure \\ The Correlation between temperature and COVID-19 Incidence: An ecologic study
}

\section{Alireza Mirahmadizadeh}

Shiraz University of Medical Sciences

Alireza Heiran

Shiraz University of Medical Sciences

Abdolrasool Hemmati

Shiraz University of Medical Sciences

Mehrzad Lotfi

Shiraz University of Medical Sciences

Mahsa Akbari

Shiraz University of Medical Sciences

Alireza forouzanrad

Shiraz University of Medical Sciences

Roya Sahebi ( $\square$ rasahebi@yahoo.com )

Shiraz University of Medical Sciences https://orcid.org/0000-0001-5231-865X

Research

Keywords: COVID-19, Climate, Temperature, Ventilation

Posted Date: October 18th, 2021

DOI: https://doi.org/10.21203/rs.3.rs-948329/v1

License: (c) (1) This work is licensed under a Creative Commons Attribution 4.0 International License.

Read Full License 


\section{Abstract \\ Background}

It has been hypothesized that the COVID-19 is less prevalent in regions with warm climates. Here we investigated the correlation between temperature and the cumulative COVID-19 incidence rate.

\section{Method}

Daily data of the temperature and the cumulative COVID-19 incidence rate were obtained from meteorological stations' reports and CORONALAB database, respectively, for every 36 counties of Fars province, southern Iran.

\section{Results}

A decreasing pattern in the cumulative incidence rate of COVID- 19 was occurred at $20-25^{\circ} \mathrm{C}$ and $25-35^{\circ} \mathrm{C}$ for counties with the cold climate and counties with the warm climate, respectively; while it was increased at both upper and lower temperatures.

\section{Conclusion}

It appears that higher rates of disease transmission at temperatures below $20^{\circ} \mathrm{C}$ and above $35^{\circ} \mathrm{C}$ might be linked to people's indoor gatherings, coupled with insufficient ventilation.

\section{Introduction}

After the emergence of the COVID-19 outbreak in Wuhan, China in late December 2019, it has quickly spread all over China and globally. The World Health Organization (WHO) declared a state of the pandemic on March 11 (1). As of September 13, 2021, COVID-19 has infected 225,488,186 individuals and caused 4,644,371 deaths, worldwide (2). In the early months of the COVID-19 pandemic, it was hypothesized that the disease is less prevalent in countries closer to the equator, where heat and humidity incline to be higher. Accordingly, the incidence rate was expected to decline in the summer; therefore, many people and policymakers hoped to get rid of the disease by the arrival of spring and summer $(3,4)$. In contrast, in some other studies, the correlation between temperature and the prevalence of COVID-19 did not show any significant difference $(1,5)$. Nevertheless, this hypothesis is not confirmed so far; contradictory results led us to assess the correlation between temperature and COVID-19 incidence rate.

\section{Methods}


In this ecologic study, we used the data of Fars province, southern Iran, to investigate the correlation between temperature and COVID-19 incidence rate. Daily data of the temperature and COVID-19 incidence rate were obtained from meteorological stations' reports and CORONALAB database, respectively, from March 21, 2020, to March 21, 2021, for each county of Fars province. The daily data about the air temperature of each county were obtained, including the minimum, maximum, and average air temperature from meteorological stations. For a uniform data visualization, average air temperature data were transformed into the ranked percentiles. In addition, the numbers of COVID-19 cases were obtained from CORONALAB database of Fars province. Then, the daily weighted cumulative incidence rate of COVID-19 (per 100,000 people) was calculated for all of the counties, separately. Finally, a correlation between the daily cumulative incidence rates and the daily air temperature was visually inspected for both the cold climate counties and the warm climate counties, obtained by Microsoft's Excel and Word software. This study was reviewed and approved by the Research Review Board of the Ethics Committee of Shiraz University of Medical Sciences (Code: IR.SUMS.REC.1399.174).

\section{Results}

Fars province, which is located in the south of Iran, has the geographical coordinates of $29^{\circ} 37^{\prime} 30^{\prime \prime} \mathrm{N}$ and $52^{\circ} 31^{\prime} 54^{\prime \prime} E(6)$, includes 36 counties, and "Shiraz" is its' seat (7). The northern counties have cold climates, and the southern ones are warm (Fig. 1). The daily air temperature is widely ranged from the lowest temperature of -11 degrees of Celsius $\left({ }^{\circ} \mathrm{C}\right)$ in "Abadeh" county to the highest temperature of $+50^{\circ} \mathrm{C}$ in "Lamerd" county. Counties were classified into three groups: (1) cold climate in winter, (2) warm climate in summer, and (3) temperate climate. Counties with temperate climates were excluded (Fig. 1). The first two groups consisted of the visual comparison for the correlation between temperature and COVID-19 incidence rate. The results showed that the cumulative incidence rate of COVID-19 was decreased by $20-25^{\circ} \mathrm{C}$ and $25-35^{\circ} \mathrm{C}$ air temperatures for counties with cold climates and counties with a warm climate, respectively; while it was increased at both upper and lower temperatures. In addition, we did not find high incidence rates at low temperatures (Fig. 2).

\section{Discussion}

Several studies have been displayed temperature as one of the factors inversely associated with COVID19 transmission $(3-5,8-10)$. But some other studies have not been attributed such a major impact to temperature and relative humidity $(1,11,12)$. Briz-Redon et al., in a study, stated that It seems the reports demonstrating the impact of warm climate on the risk of transmission of COVID-19 cannot be satisfying for controlling the pandemic. Moreover, they suggested selecting data from small areas, for example, a single country might be more advisable for such analysis (3). Huang et al, reported that $60 \%$ of confirmed COVID-19 cases occurred in spaces with the temperature ranging from $5^{\circ} \mathrm{C}$ to $15^{\circ} \mathrm{C}$ (8). Similarly, Sobur et al., showed $93.5 \%$ of confirmed COVID-19 cases occurred in temperature between $1^{\circ} \mathrm{C}$ to $16^{\circ} \mathrm{C}(1)$. The present study found the cumulative COVID-19 incidence rate was roughly declined at 20 to $35^{\circ} \mathrm{C}$. It appears that the higher rates of disease transmission at both lower and higher temperatures might be due to the indoors gathering of people in cold and warm temperatures' that is, doors and windows are 
closed at houses, offices, and public buildings to prevent energy-wasting, which cased to the insufficient ventilation of indoor spaces and subsequently, higher risk of disease transmission. By and large, as this is strongly proved that sufficient ventilation at closed spaces can reduce transmission of disease (13), perhaps the temperature itself does not control the transmission of disease and it would be rather related to the proper social response to the temperature fluctuations. However, this is just a hypothesis, which needs to be further established. In addition, in contrast with in-line publications, we did not find high incidence rates at low temperatures. One explanation might be the indirect social isolation in very cold weather. A major limitation of our study was about lack of accounting for several major protective measures against COVID-19 transmission including adherence to social distancing, wearing masks, and hand hygiene as confounders (13).

\section{Conclusion}

Our study suggested that the cumulative incidence rate of COVID-19 was decreased at 20-35 $\mathrm{C}$, partially, because of more sufficient ventilation of indoor spaces. Further studies are recommended to warrant the plausible confounders.

\section{Declarations}

\section{Ethics approval and consent to participate}

Not applicable.

\section{Consent for publication}

Not applicable.

\section{Availability of data and materials}

Not applicable.

\section{Competing interests}

The authors declare that there are no competing interests.

\section{Funding:}

The Authors did not receive any specific grant from funding agencies in the public, commercial, or not-forprofit sectors.

\section{Authors' contributions}

AM carried out the literature review, the study selection, data extraction, doing statistical analysis. $\mathrm{AH}$ helped in statistical analysis and contributed to the writing of the manuscript. ARH and ML contributed to 
writing of the manuscript. MA and ALF contributed to the data extraction.RS carried out the literature review, data extraction and Writing the manuscript. All authors have helped with data interpretation. The authors read and approved the final manuscript.

\section{Acknowledgements:}

The authors wish to thank the Research Affairs Department of Shiraz University of Medical Sciences for their financial support.

\section{References}

1. Sobur MA, Islam MS, Haque ME, Haque MT, Toniolo A, Rahman MT. Temperature and relative humidity are not major contributing factor on the occurrence of COVID-19 pandemic: An observational study in 57 countries. medRxiv. 2020.

2. Available:. https://www.worldometers.info/coronavirus/.

3. Briz-Redón Á, Serrano-Aroca Á. The effect of climate on the spread of the COVID-19 pandemic: A review of findings, and statistical and modelling techniques. Progress in Physical Geography: Earth Environment. 2020;44(5):591-604.

4. Notari A. Temperature dependence of COVID-19 transmission. Science of The Total Environment. 2021;763:144390.

5. Kassem AZE. Does temperature affect COVID-19 transmission? Frontiers in public health. 2020;8:934.

6. Available:. http://GeoHack.toolforge.org.

7. Available:. https://fa.wikipedia.org/wiki.

8. Huang Z, Huang J, Gu Q, Du P, Liang H, Dong Q. Optimal temperature zone for the dispersal of COVID-19. Science of The Total Environment. 2020;736:139487.

9. Mandal CC, Panwar MS. Can the summer temperatures reduce COVID-19 cases? Public Health. 2020;185:72-9.

10. Ozyigit A. Understanding Covid-19 transmission: The effect of temperature and health behavior on transmission rates. Infection disease health. 2020;25(4):233-8.

11. Available:. https://covid-19.conacyt.mx/jspui/handle/1000/77.

12. Jüni $P$, Rothenbühler $M$, Bobos $P$, Thorpe KE, Da Costa BR, Fisman DN, et al. Impact of climate and public health interventions on the COVID-19 pandemic: a prospective cohort study. Cmaj. 2020;192(21):E566-E73.

13. Morawska L, Tang JW, Bahnfleth W, Bluyssen PM, Boerstra A, Buonanno G, et al. How can airborne transmission of COVID-19 indoors be minimised? Environment international. 2020;142:105832.

\section{Figures}




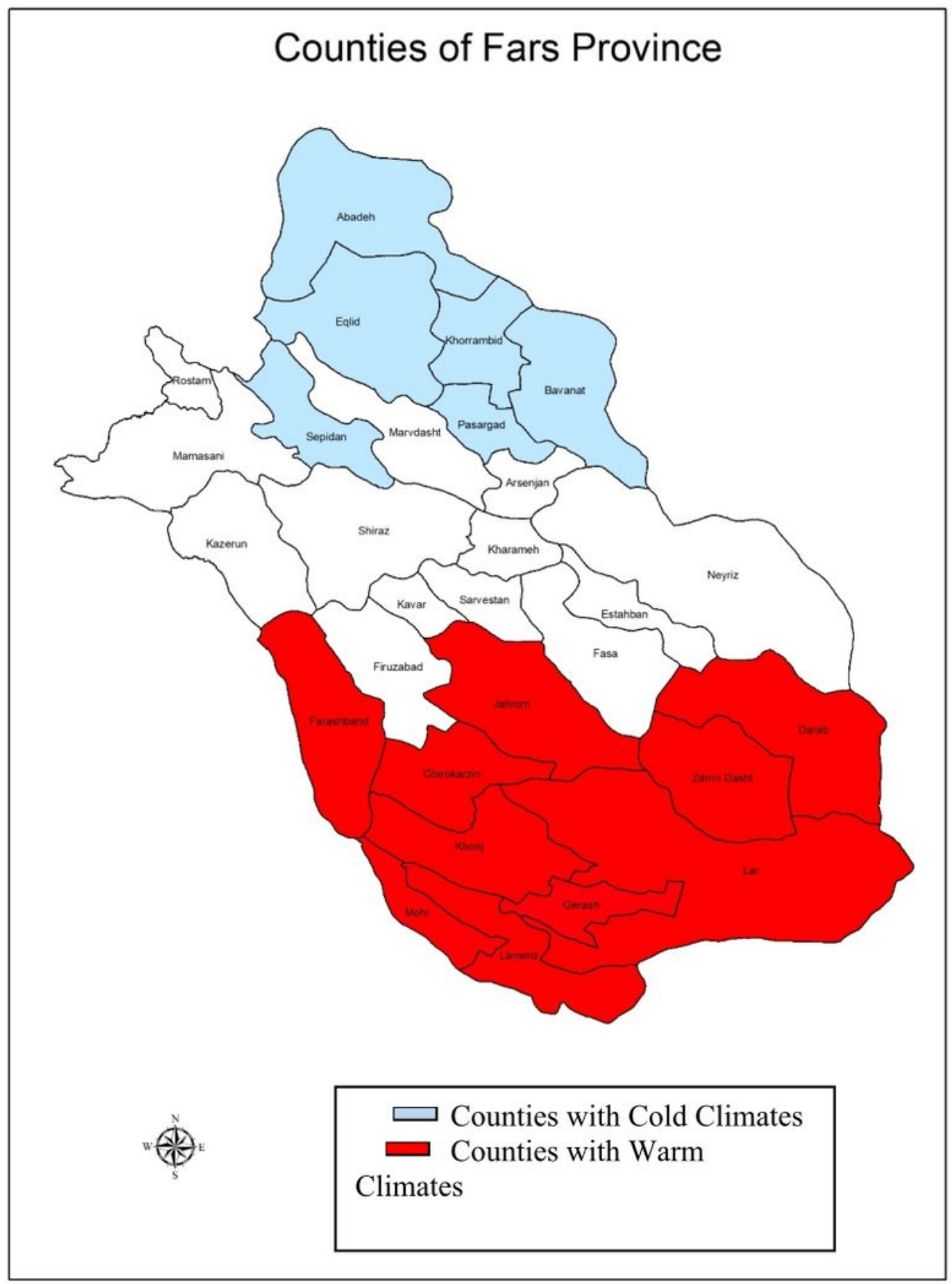

Figure 1

Location of Fars province counties with cold and warm climates 


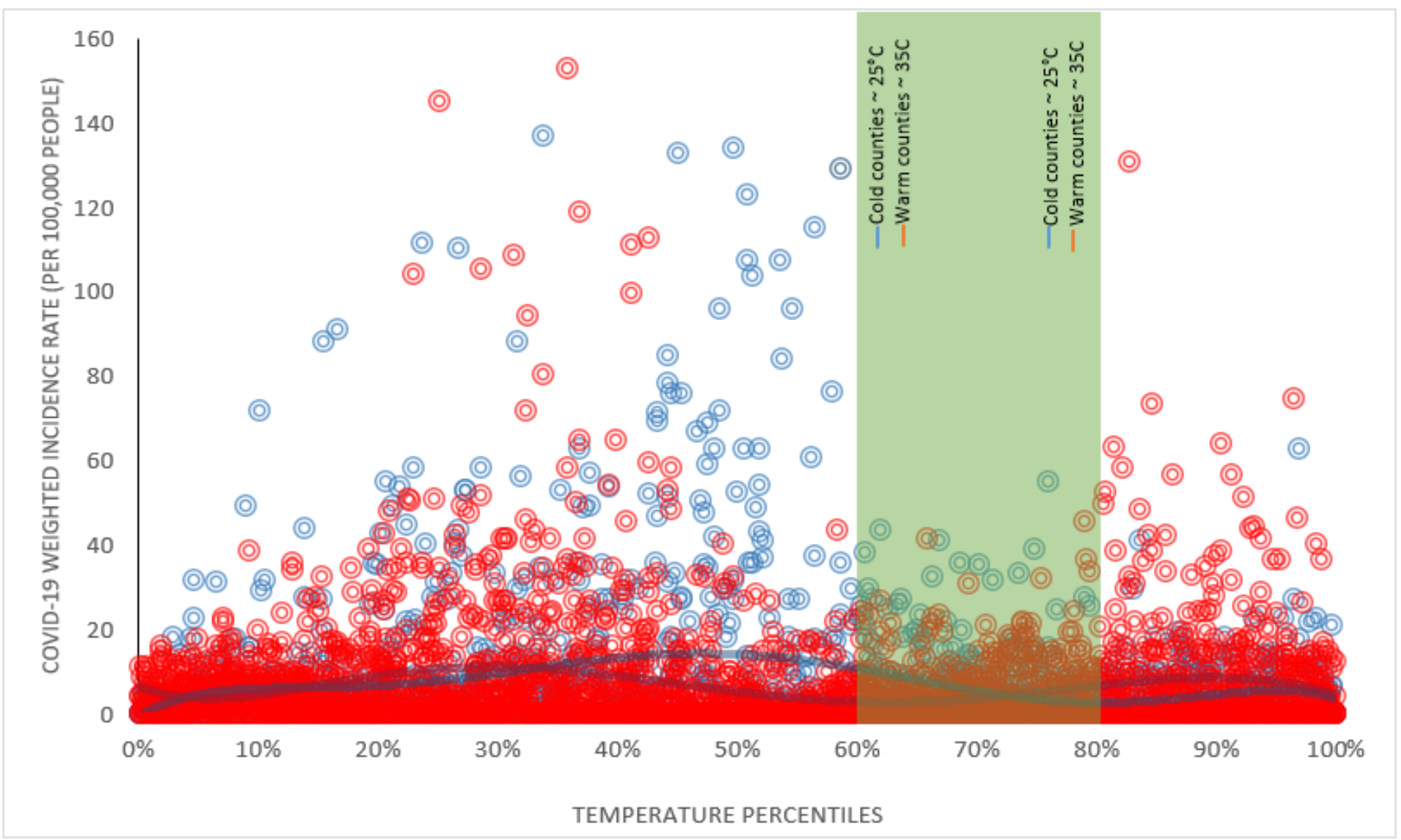

Figure 2

Cumulative weighted incidence rate of COVID-19 against temperature percentiles in warm climate (red dots and curve) and cold climate (blue dots and curve) 